\title{
O caos sanitário da crise por COVID-19 no Brasil e o direito à saúde na jurisprudência do Supremo Tribunal Federal
}

The sanitary chaos of the COVID-19 crisis in Brazil and the right to health in the Supreme Federal Court's jurisprudence

El caos sanitario de la crisis del COVID-19 en Brasil y el derecho a la salud en la jurisprudencia del Supremo Tribunal Federal

Krishina Day Ribeiro ${ }^{1}$

Leandro Cavalcante Lima²

Samara Manuela C. de Souza ${ }^{3}$

Kevyson Eduardo Pimentel ${ }^{4}$

\begin{abstract}
Resumo
Investiga-se os pressupostos do caos sanitário no Brasil por COVID-19 e como o sistema judicial decide em relação ao enfrentamento da epidemia. Observa-se que a crise, em sua complexidade, causa uma desorganização, que é resultante de dois fenômenos: o federalismo descoordenado e a constitucionalização simbólica. A metodologia adotada resulta de pesquisa qualitativa com a técnica de análise de conteúdo. Para testar a hipótese da análise foram coletados dois acórdãos da jurisprudência temática sobre COVID-19 do site do Supremo Tribunal Federal, em que se mediu a frequência das categorias teóricas estudadas. Tem-se por resultado que o caos sanitário é acentuado com a alteração da lógica federativa em relação à centralização de poder referente à União sobre os demais entes federativos, somado ao processo de constitucionalização simbólica que afeta os países periféricos como o Brasil.
\end{abstract}

Palavras-chave

COVID-19. Direito à Saúde. Jurisprudência. Federalismo. Constituição.

\begin{abstract}
The presuppositions of the sanitary chaos in Brazil are investigated by COVID-19 and how the judicial system decides in relation to the fight against the epidemic. It is observed that the crisis, in its complexity, causes disorganization which is the result of two assumptions: the uncoordinated federalism and the symbolic constitutionalization. The adopted methodology results from qualitative research with the technique of content analysis. To evaluate the hypothesis of this analysis, two judgments from the thematic jurisprudence on COVID-19 were collected from the website of the Supreme Court, in which the frequency of the studied theoretical categories was measured. As a result, the sanitary chaos is accentuated with the alteration of the federative logic in relation to the centralization of power related to the Union

\footnotetext{
${ }^{1}$ Doutora em Desenvolvimento Socioambiental, Universidade Federal do Pará, Belém do Pará, PA, Brasil; professora adjunto I, Faculdade de Direito, Instituto de Ciências Jurídicas, Universidade Federal do Pará, Belém do Pará, PA, Brasil. https://orcid.org/0000-0003-2180-8503. E-mail: krishina.ribeiro@gmail.com

2 Especialista em Direito Civil e Processual Civil, Faculdade de Estudos Administrativos de Minas Gerais, Belo Horizonte, MG, Brasil; bacharel em Direito, Universidade Federal do Pará, Belém, PA, Brasil; advogado, Ordem dos Advogados do Brasil, Curitiba, Paraná, Brasil. https://orcid.org/0000-0001-6371-3612. E-mail: leandrocavalcantelima@gmail.com

${ }^{3}$ Graduanda em Direito na Universidade Federal do Pará, Belém, PA, Brasil; bolsista voluntária, Universidade Federal do Pará, Belém, PA, Brasil. https://orcid.org/0000-0003-0242-6470. E-mail: samara19.correa@gmail.com

${ }^{4}$ Graduando em Direito, Universidade Federal do Pará, Belém, PA, Brasil; bolsista de Iniciação Científica, Universidade Federal do Pará, Belém, PA, Brasil. https://orcid.org/0000-0002-1083-3749. E-mail: kevysoneduardo1@gmail.com
} 
over the other federative entities, added to the symbolic constitutionalization process that affects peripheral countries like Brazil.

\section{Keywords}

COVID-19. Right to Health. Jurisprudence. Federalism. Constitution.

\section{Resumen}

Los presupuestos del caos sanitario en Brasil son investigados por COVID-19 y cómo el sistema judicial decide sobre la lucha contra la epidemia. Se observa que la crisis, en su complejidad, causa una desorganización que é resultado de dos supuestos: el federalismo descoordinado y la constitucionalización simbólica. La metodología adoptada es el resultado de una investigación cualitativa con la técnica de análisis de contenido. Para contrastar la hipótesis de este análisis, se recogieron dos sentencias de la jurisprudencia temática sobre COVID-19 del sitio web de la Corte Suprema, en las que se midió la frecuencia de las categorías teóricas estudiadas. Como resultado, el caos sanitario se acentúa con la alteración de la lógica federativa en relación con la centralización del poder relacionado con la Unión sobre las demás entidades federativas, sumado al proceso simbólico de constitucionalización que afecta a países periféricos como Brasil.

\section{Palabras clave}

COVID-19. Derecho a la salud. Jurisprudencia. Federalismo. Constitución.

\section{Introdução}

O novo coronavírus 2 da síndrome respiratória aguda grave (SARS-CoV-2, em inglês), cuja doença foi denominada pelo Organização Mundial da Saúde (OMS) de COVID-19 (coronavirus disease 19), foi identificado em dezembro de 2019 em Wuhan, na China, se disseminando em uma pandemia que contabiliza 233.955.450 casos confirmados e 4.787.007 óbitos no mundo (1). Desse quadro, o Brasil registra $9,1 \%$ dos infectados (21.427.073) e 12,4\% dos mortos (596.749) (2).

Para a governança global em saúde, a contenção dos danos causados pela SARSCoV-2 exigiria uma atenção especial às doenças não infecciosas e à desigualdade socioeconômica como fatores intensificadores da crise sanitária. Não obstante, observou-se que fatores políticos e sociais foram os maiores impulsionadores da força devastadora da COVID-19, notadamente em países como EUA, Índia e Brasil: um fenômeno descrito como sindemia (3) (4).

No Brasil, de fato, a vulnerabilidade socioeconômica, em vez de idade, estado de saúde e outros fatores de risco, afetou o curso da pandemia com uma carga adversa desproporcional sobre estados e municípios mais pobres. A região Norte - com menores índices de desenvolvimento socioeconômico, de recursos hospitalares (tanto público, quanto privado), de leitos e médicos de Unidades de Tratamento Intensivo (UTI) per capita amargou as maiores taxas de mortalidade em 2020 (5). 
Globalmente várias medidas públicas sociais e de saúde foram implementadas para suprimir e mitigar a disseminação do SARS-CoV-2, incluindo o uso de máscaras, restrições de viagens, teste intensivo para rastrear e isolar infectados, distanciamento físico/social, fechamento de escolas, fechamento de locais de trabalho, proibição de eventos públicos (esportivos, festivos e religiosos), restrições ao tamanho dos encontros, fechamento do transporte público, toque de recolher e bloqueios nacionais e locais à locomoção. As evidências empíricas demonstraram que tais medidas foram eficazes em controlar a disseminação da pandemia, porém algumas delas resultaram um alto custo econômico e social (6). Com efeito, o Fundo Monetário Internacional (FMI) estimou para 2020 contração na economia global de $-3,5 \%$ e no Brasil de $-4,5 \%$ (7).

A Organização Mundial da Saúde reuniu experts mundiais no tema e os governos que a integram para divulgar conhecimento científico e recomendações para a prevenção e o tratamento da COVID-19. As diretrizes internacionais foram incorporadas pelo Brasil com a Lei $n^{\circ} 13.979 / 2020$ para enfrentar a emergência sanitária, dentre outros atos normativos. Contudo, o esforço foi em parte comprometido pela politização e pelo discurso ideológico do Presidente da República (8-11). O governante negou a importância dos impactos da pandemia sobre a saúde coletiva, dando ênfase às vantagens econômicas da livre circulação de pessoas e mercadorias. Assim, ficou inerte na coordenação de ações e na criação de uma política nacional para orientar estados e municípios, especialmente no âmbito do Ministério da Saúde. O efeito político-administrativo se deu em cascata, mobilizando os sectários políticos, empresariado e movimentos sociais alinhados ao discurso do Presidente.

Constatou-se uma relação direta entre os atos normativos federais e a obstrução constante às respostas locais, incrementada com o discurso do Presidente contra a saúde pública: i) defesa da tese da imunidade de rebanho (ou coletiva) por contágio (ou transmissão); ii) incitação constante à exposição; iii) banalização das mortes e das sequelas causadas pela doença; iv) obstrução sistemática às medidas de contenção promovidas por governadores e prefeitos; v) foco em medidas de assistência e abstenção de medidas de prevenção; vi) ataques a críticos da resposta federal, à imprensa e ao jornalismo profissional; vii) consciência da irregularidade de determinadas condutas (12). O resultado foi desastroso, aprofundando a crise e instalado o caos sanitário $(13,14,15)$.

Diante desse quadro, a Organização Mundial da Saúde, em seu artigo 21, fixou competência para adotar regulamentos relativos a requisitos sanitários, de quarentena e outros procedimentos, destinados a prevenir a propagação e contenção de epidemias e pandemias. Portanto, os Estados-membros estão vinculados aos cumprimentos de suas 
recomendações, bem como há a obrigação de apresentarem relatórios de cumprimentos de suas disposições, pois é por meio desses dados que se acompanha a situação sanitária e de saúde dos países com o fim de controlar a crise.

Em janeiro de 2020, após a notificação da China, o comitê da OMS se reuniu para requerer os dados que o país havia coletado para decidir sobre as primeiras providências contra a COVID-19. Em 23 de janeiro do mesmo ano, os Estados foram advertidos para adotarem medidas de quarentena e, no dia 30, foi decretado estado de emergência, tendo o surto sido declarado como pandemia em 11 de março de 2020. Iniciaram-se assim, as medidas de contenção, tratamento e prevenção da infecção. Dentre elas as restritivas de direitos, "vez que o controle de fronteiras e o bloqueio feito sem a avaliação da situação das pessoas e dos serviços que precisam transitar entre os países, poderia agravar ainda mais a situação da pandemia" (16)

Instalada a crise sanitária no Brasil, exigiu-se do sistema político medidas vinculantes para amparar a população, sendo necessária a tomada de decisões legislativas, ao se perceber que o sistema de saúde precisava ganhar tempo para produzir formas que garantissem a imunização e a proteção das pessoas e, assim salvar vidas.

Para responder aos objetivos deste artigo, dividiu-se o mesmo em partes: na primeira parte, aborda-se federalismo descoordenado no cenário da crise; em seguida, investiga-se a concretização do Direito à Saúde e a Constitucionalização Simbólica; posteriormente, constrói-se a metodologia da pesquisa que permeou o artigo com a técnica de análise de conteúdo. Por fim apresentam-se resultados e análises.

\section{O federalismo descoordenado no cenário da crise sanitária}

Na crise sanitária, foram adotadas estratégias cientificamente comprovadas para evitar o aumento exponencial de pessoas contaminadas por SARS-CoV-2. Contudo, houve discordância entre o Presidente da República e as recomendações sobre os procedimentos de enfrentamento da crise:

(...) o Chefe do Poder executivo demonstrou-se contrário a medidas como lockdown, ou seja, fechamento de todos os estabelecimentos comerciais e industriais e isolamento social, ou a medidas menos abrangentes, pretendendo que fossem mantidos abertos os estabelecimentos comerciais e que todas as atividades funcionassem normalmente, pois dizia que se tratava de "uma gripezinha", mencionando que passaria rápido e, ainda, dizendo expressamente, que "todos iremos morrer um dia" e que, portanto, tínhamos de enfrentar essa doença como homens (Fala Presidencial pronunciada em 29/03/2020) (17) 
Com a pandemia, a crise sanitária agravou-se pela alteração da lógica federativa constitucional. No Brasil, a forma de Estado é o federalismo, por esse motivo a autonomia dos entes federados (estados-membros e municípios) é garantida, respeitados os limites e as competências estipuladas no corpo constitucional. Tal modelo pressupõe que "[...] governos locais que gastam mais eficientemente, são mais accountable para suas populações e políticas públicas, respondendo melhor a particularidades locais." (18), ainda mais considerando a dimensão continental do território brasileiro, que necessita de um aparato administrativo habilitado para responder às adversidades.

O federalismo descoordenado que agrava a crise sanitária é formado a partir de uma série de eventos que dificultam o andamento das políticas públicas e, por isso, impedem uma gestão eficiente para enfrentar a disseminação do vírus e o colapso no sistema básico de saúde. Dentre os fatores que permeiam os conflitos atuais da República Federativa brasileira, é patente as discordâncias entre as entidades federativas advindas das inúmeras tentativas de centralizar o poder nas mãos da União. O delinear desse embate surge antes mesmo da declaração da pandemia de COVID-19 pela Organização Mundial da Saúde, mas com a ascensão do governo Bolsonaro acaba por alterar a estabilidade institucional e acelerar o processo de concentração das funções ao Poder Executivo (18).

Remetendo-se ao contexto histórico brasileiro observa-se a transformação do modelo federativo atual, principalmente durante o Governo Varguista e o Regime Militar, em que se observaram atitudes extremamente autoritárias que colocavam os demais poderes em papéis secundários de atuação. A partir de 1988, com o avanço da construção de um país elencado à democracia, constatou-se uma maior cooperação entre os Estados e a União a fim de que fosse firmado e fortalecido os direitos positivados na Constitucional Federal; justamente neste cenário que o surge o Sistema Único de Saúde com um papel fundamental de promover a saúde a todos os cidadãos brasileiros, ao instituir no Art. 196 da Constituição Federal de 1988 (CRFB):

\footnotetext{
A saúde é direito de todos e dever do Estado, garantido mediante políticas sociais e econômicas que visem à redução do risco de doença e de outros agravos e ao acesso universal e igualitário às ações e serviços para sua promoção, proteção e recuperação (19).
}

Antes mesmo de ser eleito, o chefe do Poder Executivo já ameaçava a integridade do regime político e, por vezes, reproduzia frases que desafiavam a estabilidade das instituições, que demoraram anos para ter um embrião democrático. Com a falta de apoio 
político de muitos governantes e prefeitos, que não aderiram aos posicionamentos bolsonaristas, iniciou-se um projeto de derrocada da cooperação entre as entidades federativas - fato esse que já era constatado antes de seu governo -, arquitetando assim a narrativa de guerra contra inimigos para "uma democracia sem mediações ou fiscalização institucional das relações entre governante e povo" (20).

A partir da decretação da pandemia do COVID-19, no dia 11 de março de 2020 pela Organização Mundial da Saúde, exigiu-se uma cooperação mundial e nacional de enfrentamento à crise sanitária. Todavia, no contexto brasileiro, ao invés de tornar o país mais forte com uma governança pública qualificada, o chefe do Poder Executivo preferiu prosseguir com o processo de alteração da lógica federativa, ignorando a capacidade destrutiva da doença.

O confronto das entidades federativas- representado pela ínfima cooperação entre as entidades na Administração Pública durante a crise sanitária e pela ausência de liderança governamental pelo Poder Executivo federal - implicou no aumento de consequências danosas para com os direitos e garantias da nação brasileira, influenciando, inclusive, nas estatísticas de óbitos e infectados, como apontado durante depoimentos na CPI da Pandemia. Na CPI, os cientistas Claudio Maierovitch e Natália Pasternak apresentaram estimativas de que o Governo Federal poderia ter evitado o óbito de 80 a 90 mil brasileiros, caso tivesse assinado o acordo com o Instituto Butantan e a Pfizer na compra das vacinas. Além disso, constataram que, se o Brasil tivesse adotado as medidas sanitárias cabíveis desde o início da pandemia e, portanto, estivesse na média mundial de controle, o país teria evitado a morte de 375 mil brasileiros.

\section{A concretização do direito fundamental a saúde e a constitucionalização simbólica}

As ações tomadas pelo governo brasileiro para a mitigação dos impactos da pandemia também dizem respeito ao funcionamento das instituições. Se por um lado, requer uma cooperação internacional de enfrentamento ao vírus, respeitando as recomendações e as diretrizes dispostas pela Organização Mundial da Saúde, também se faz mister a articulação nacional para adoção de medidas necessárias a fim de conter os impactos da crise em nível interno (21).

Tem-se verificado que, em relação ao federalismo descoordenado, o embate constante entre os governadores estaduais e municipais - que decidem pela aplicação de medidas restritivas de locomoção - e o chefe do Poder Executivo - que atua em prol da flexibilização das determinações sanitárias - pressiona o sistema de saúde brasileiro, que necessita de 
uma resposta rápida e eficaz para conter o avanço do vírus. Tal fato leva constantemente o Supremo Tribunal Federal a versar, por meio de exame jurisprudencial, sobre as medidas sanitárias em tempo pandêmico (22).

No cenário onde se desenvolve essas observações científicas, há também um outro agravante da crise sanitária, em particular encaminha-se o processo de constitucionalização simbólica.

A atual complexidade de nossa sociedade pode ser observada pelo acoplamento dos sistemas jurídico e político. Sistemas acoplados são os que funcionam juntos: o sistema jurídico exerce a função de interpretar e aplicar a lei; o sistema político exerce a função de legislar. Ambos são mediatizados pela Constituição, que é compreendida como aquisição evolutiva da sociedade moderna mediatiza a influência recíproca entre os sistemas jurídico e político acoplados (23). A Constituição, portanto, não representa uma via de prestações recíprocas, mas é o resultado de interpenetração sistêmica, que ocasiona irritações entre o sistema político e jurídico. A constitucionalização é, portanto, fruto do processo de constitucionalismo, que busca afirmar a entrega de direitos fundamentais com bases democráticas de funcionamento do sistema, contrário ao regime arbitrário. (24).

Pelo prisma sistêmico, a Constituição apresenta-se como texto autológico, que se propõe a ser em parte de direito. Sua autologia reside no fato de que o fundamento do direito está na própria Constituição. Logo, prevê soluções políticas para o problema da autorreferencialidade do direito e soluções jurídicas para o problema da autorreferencialidade da política. Concebida como uma instância interna do sistema jurídico, é lei suprema do Estado. Como instância do sistema político, tanto atua na política instrumental, que modifica decisões, como atua na política simbólica, que não modifica situações $(24,25)$.

A constitucionalização simbólica refere-se ao simbólico no contexto da legislação em que o relevante é o significado latente, onde o discurso conotativo é mais forte que o discurso denotativo, ou seja, decorre que o texto normativo em parte tem funções latentes, que são mais fortes, de natureza político-simbólica, bem mais impactantes socialmente, do que a função manifesta de natureza jurídico-normativa. Neves utiliza um exemplo para compreensão dessa carga simbólica da Constituição:

[l]egislação simbólica como legislação álibi: ocorre quando há comoção pública que diante de um público aflito, o Estado reage produzindo um álibi para acalmar o público. Em 1987 idosos que estavam em hotéis do lado norte contaminados por peixe, e alguns morreram. Em face disso chocada a população, fortemente orientada para o turismo de pessoas idosas, hotéis 
perderam clientes, empresas pesqueiras tiveram déficit no lucro. Então publicou-se um decreto que restringia a atividade dos barcos pesqueiros na área. Os idosos voltaram a se divertir nos hotéis do lago norte. Mas não havia estrutura organizacional para cuidar do controle. O Decreto permaneceu ineficaz. Mas teve um álibi tranquilizador para apontar que o Estado estava preocupado e atuante para proteger tais idosos. Um texto que não tinha significado prático. (23)

Dessa forma, a constituição-álibi se refere à atividade constituinte em que o texto e o discurso funcionariam como álibi para os legisladores constitucionais e os governantes. No exemplo acima, observa-se a atividade constitucional de normatização de uma situação para acalmar a população envolvida no caso da morte de pessoas idosas, contaminadas por veiculação hídrica. Observa-se assim que a legislação-álibi reforça a corrosão do acoplamento porque a carga político-simbólica do diploma legal prevalece sobre a função normativo-jurídica do dispositivo legal, o que ocasiona efeitos sobre a autonomia do sistema jurídico e impede a efetividade da concretização constitucional de direitos fundamentais no estado democrático.

\section{Metodologia}

Este artigo teve sua pesquisa desenhada a partir do seguinte problema de pesquisa: quais os pressupostos do caos sanitário no Brasil por COVID-19 e como o sistema judicial vem decidindo em relação ao enfrentamento da crise sanitária? Estabelecida tal pergunta, passou-se à coleta dos acórdãos. Coacci (26) convida o pesquisador a desenhar a sua pesquisa, que é pensar em como desenvolver um problema de pesquisa sólido, mobilizar corretamente a teoria, selecionar dados de qualidade e realizar articulações válidas entre dados e teoria. Um bom desenho de pesquisa deve levar em conta a escolha de um acórdão, que deve representar o problema; os pontos fortes e fracos do acordão; o método e a técnica que podem ser utilizados na pesquisa (27). Acórdão é a decisão judicial proferida em segundo grau de jurisdição por uma câmara/turma de um Tribunal. Os julgados recebem esse nome por serem proferidos de forma colegiada e refletirem o acordo de mais de um julgador. O acórdão pode ser unânime ou não unânime. Diferentemente, a jurisprudência são decisões reiteradas dos Tribunais. É a forma de revelação do direito que se processa através do exercício da jurisdição, em virtude de uma sucessão harmônica de decisões dos tribunais.

Para a realização desta investigação empírica, escolheu-se a técnica da análise de conteúdo. É a técnica de análise de comunicações, aplicada a discursos políticos, manuais escolares, entrevistas, dentre outros. A sua aplicação a acórdãos jurisprudenciais permite 
explicitar e sistematizar os conteúdos das mensagens. A técnica visa conhecer aquilo que está por trás das palavras, os sentidos sutis dos textos, para além de descrever seus conteúdos. Em ciências humanas, a análise de conteúdo busca a inferência, em sua faceta qualitativa. A técnica permite ligar a descrição (levantamento de dados, análise quantitativa) com as diferentes interpretações possíveis (análise qualitativa), conforme o marco teórico previamente definido. Pode-se organizar as fases da técnica (27):

(1) Pré-análise: organização da pesquisa com a escolha dos documentos, formulação de hipótese e dos objetivos, elaboração dos indicadores que fundamentarão a interpretação. Nessa fase, lê-se os documentos a analisar (leitura flutuante), sem deixar de fora qualquer elemento que não possa ser justificável no plano do rigor científico;

(2) Exploração do material: momento da codificação e da categorização, relaciona-se elementos do conteúdo coletado com os referenciais teóricos, para que inferências e interpretações possam ser feitas na fase seguinte. A codificação é a escolha das unidades, enumeração escolha da regra de contagem para quantificação e a classificação/agregação é a escolha das categorias. Dessa fase, destaca-se dois recortes:

(2.1) unidade de registro: segmento do conteúdo a considerar como unidade base, unidade de significação a codificar, como a palavra, o tema, o objeto ou referente, o personagem, o acontecimento, o documento;

(2.2.) unidade de contexto: segmento da mensagem utilizada para compreender a significação exata da unidade de registro, serve de unidade de compreensão para codificar a unidade de registro. A última fase corresponde ao tratamento dos resultados, inferência e interpretação conforme o marco teórico abordado.

Nesta pesquisa, escolheu-se trabalhar com dois acórdãos. O primeiro foi a Ação Direta de Inconstitucionalidade (ADI) $n^{\circ}$ 6.343, ajuizada pelo partido Rede Sustentabilidade, que levou ao Supremo Tribunal Federal a inconstitucionalidade de uma série de dispositivos da Lei $n^{\circ} 13.979 / 2020$, alterados pelas Medidas Provisórias $n^{\circ} 926$ e $n^{\circ} 927$ em relação à Constituição Federal (28).

O outro acórdão escolhido trata-se da Arguição de Descumprimento de Preceito Fundamental (ADPF) n 709, a, proposta pela Articulação dos Povos Indígenas do Brasil (APIB); Partido Socialista Brasileiro (PSB); Partido Socialismo e Liberdade (PSOL); Partido Comunista do Brasil (PC do B); Rede Sustentabilidade (Rede); Partido dos Trabalhadores (PT); e Partido Democrático Trabalhista (PDT). A ação teve por objeto um conjunto de atos comissivos e omissivos do Poder Público, relacionados ao combate à pandemia por COVID19, que implicariam alto risco de contágio e de extermínio de diversos povos indígenas, em 
violação à dignidade da pessoa humana (CRFB, art. $1^{\circ}$, inc. III), aos direitos à vida (CF, art. $5^{\circ}$, caput) e à saúde (CRFB, arts. $6^{\circ}$ e 196), bem como ao direito de tais povos a viverem em seu território, de acordo com suas culturas e tradições (CRFB, art. 231) (29).

\section{Resultados e discussão}

Em síntese, os dados extraídos das decisões ADFP N 709 e ADI № 6.343 a presentam a seguinte frequência de conteúdo:

Tabela 1. Categorias identificadas

\begin{tabular}{lccc}
\hline \multicolumn{1}{c}{ Categorias } & Frequência & ADPF $\mathbf{~}^{\mathbf{0}} \mathbf{7 0 9}$ & ADI $^{\mathbf{0}} \mathbf{6 . 3 4 3}$ \\
\hline Federalismo descoordenado & 30 & 18 & 12 \\
Crise sanitária & 22 & 19 & 3 \\
Constitucionalização simbólica & 11 & 8 & 3 \\
\hline
\end{tabular}

Fonte: Os autores

\section{Federalismo descoordenado}

Sendo construída a análise dos dados, a orientação da pergunta metodológica com base teórica visou perquirir quais os argumentos que descrevem a descoordenação entre os poderes em cenário pandêmico por COVID-19.

O federalismo no Brasil apresenta-se com duas temporalidades. A primeira temporalidade é pós-1988, cujo arranjo federativo da Constituição de 1988 buscou equilibrar objetivos nacionais de welfare state (estado de bem-estar social) e implementação subnacional descentralizada e autônoma. Nesse cenário, foram criados sistemas de políticas públicas garantindo a participação dos governos dos entes federativos no processo decisório federativo.

Resultado desse processo é o Sistema Único de Saúde, que foi construído com base em diretrizes nacionais de normatização e redistribuição de recursos, sendo o repasse fundo a fundo um exemplo; de implementação descentralizada, como os níveis de atenção em saúde; de espaços institucionais de participação social, como os Conselhos de Saúde; e de negociação intergovernamental, a exemplo da Comissão Tripartite. Tais diretrizes se traduzindo num exemplo de democracia participativa.

Contudo, a segunda temporalidade é observada em relação a um outro federalismo, o federalismo bolsonarista, adverso aos ideais da CRFB/88, especialmente contra a expansão da atividade governamental exigida pelo crescimento dos direitos de cidadania e dos checks and balances. O projeto neopopulista defende uma democracia sem mediações ou 
fiscalizações institucionais das relações entre governante e povo. Logo, é um projeto adverso às boas práticas de governança pública, como sugeridas pelo Tribunal de Contas da União e organismos multilaterais, a exemplo da OMS.

O projeto bolsonarista reduziu os espaços de diálogo, negociação e participação dos entes federativos. Exemplo dessa observação é o acordão ADPF n 709 . Nesse julgado, o Tribunal observou a ausência de diálogo institucional e a consequente necessidade de se concretizar tal diálogo, pois esse caso exige a elaboração de planos de gerenciamento para o enfrentamento da crise sanitária dos povos originários. Esses mecanismos de democracia participativa (diálogos institucionais) entre Poder Executivo e Poder Judiciário necessitam existir para o monitoramento e a execução de referido plano.

O STF informa da existência de Plano de Contingência na ADPF, mas não de um plano de enfrentamento, que considere as particularidades das diferentes etnias. A realidade complexa requer a expertise de profissionais abalizados sobre a cultura indígena, fato que demonstra a necessidade de diálogo institucional entre órgãos do Poder Executivo e Judiciário.

Há a mesma constatação na $A D I n^{\circ}$ 6.343. Nesse julgado, a possibilidade de restrição à locomoção que quis impor a União Federal subtraía a competência dos Estados, Distrito Federal e Municípios, uma vez que a imposição de restringir a locomoção intermunicipal e intramunicipal dependia de recomendação técnica do Ministério da Saúde, bem como da Agência de Vigilância Sanitária, segundo está previsto em seu parágrafo $3^{\circ}$, inciso VI, b da Lei $13.979 / 202$.

Ao se aplicar a técnica de análise de conteúdo, estabelecem-se ancoragens do conteúdo que norteiam a posição do Supremo Tribunal Federal sobre a matéria (28):

1. Nenhum ente federativo, nenhum Poder de Estado, nenhuma autoridade, tem o monopólio do combate à pandemia.

2. Enquanto entes federativos continuarem brigando judicialmente quem sofre é a população.

Os dados apontam que a análise do acórdão confirmou o entendimento do STF sobre a competência administrativa e legislativa em matéria de saúde pública, em relação ao poder público federal, devendo ser repartida entre os entes federativos (saúde, art. 23, II, art. 24, XII da CFRB) (19).

A lógica federativa bolsonarista desequilibrou o arranjo institucional emergente da CRFB, pois aposta em um modelo dualista, autocrático e de confronto intergovernamental. As disputas entre o presidente e os governadores sobre o afastamento unilateral pelo Poder 
Executivo federal de competências constitucionais pela promulgação da Lei $n^{\circ}$ 13.979/2020 (art. $3^{\circ}, \mathrm{VI}, \S \S 6^{\circ}, 6^{\circ}-\mathrm{A}$ e $7^{\circ}, \mathrm{II}$ ), a qual restringia a execução pelos Estados e municípios de medidas administrativas de gerenciamento da crise, consistindo em uma manobra normativa, que advém de uma decisão estratégica contrária à gestão compartilhada da crise sanitária, pois aprofunda a assimetria entre as partes interessadas.

Entende ainda o Supremo Tribunal Federal que as divergências entre representantes do Poder Público, representantes interfederativos e entre autoridades do mesmo nível de governo levam à falta de confiança e insegurança institucionais, o que contribui para a crise sanitária. Ainda, segundo o entendimento do referido órgão, a visão do Poder Executivo federal de que somente a União deve gerenciar segmentos públicos, a exemplo da questão do transporte intermunicipal e a implementação de barreiras sanitárias, desorganiza o gerenciamento compartilhado da crise sanitária. Por um lado, tem-se a supressão de competências pela União Federal em relação aos Estados e Municípios, como ficou patente na ADI n 6.343; por outro, na ADPF n 709 constata-se omissão constitucional.

O federalismo coordenado consiste em instituto democrático que se realiza pela estrita adesão às regras do jogo constitucional, o que requer preservação do direito à saúde e as condições de sua promoção em território nacional. No que diz respeito ao enfretamento da crise sanitária, não se mostra razoável subtrair competência dos Estados, Distrito Federal e Municípios ao restringir a locomoção interestadual e intermunicipal, atrelando a essa restrição recomendação técnica do Ministério da Saúde, haja vista que nenhum ente federativo tem o monopólio de combate à pandemia. Nesse sentido, a descoordenação deve ceder lugar à coordenação do federalismo, que consiste no enfrentamento da crise sanitária de forma conjunta e compartilhada.

Soma-se a essa observação que a omissão por parte do Governo Federal também contribui para a desorganização da crise sanitária. Em exame à ADPF n 709, a decisão destaca a omissão por parte do governo federal em relação à invasão de terras indígenas que resultam em práticas de crimes ambientais - e à ausência de sua repressão (promoção de desintrução). Além dessas omissões, o Poder Executivo federal se manifesta no sentido de não atender as necessidades sanitárias dos povos originários e somente prestará serviços, administrados pelas Secretaria Especial de Saúde Indígena (Sesai) e Fundação Nacional do Índio (Funai), para indígenas aldeados em terras homologadas, deixando a descoberto as necessidades sanitárias de grande parte dos povos indígenas que estão em terras não-homologadas. 
A ADPF n 709 descreve a baixa concretização de políticas públicas e a consequente atuação incipiente da União em relação ao direito à saúde de povos originários em cenário pandêmico. A Articulação dos Povos Indígenas no Brasil (APIB) aponta uma subnotificação no número de casos e de mortes divulgados pelo Ministério da Saúde pelo Boletim Especial Epidemiológico (BEE), motivo pelo qual a instituição faz levantamento independente, demonstrando um número consideravelmente maior de indígenas infectados e de mortes. O STF atendeu à maioria dos pontos levantados pelo requerente, e definiu a exigência de uma nova política pública de enfrentamento à COVID-19 dentro das comunidades indígenas.

\section{Crise sanitária}

Em investigação ao acordão ADI n 6343, o STF entende a crise sanitária representa uma séria ameaça à organização de políticas públicas que visam proteger a vida, a saúde e o bem-estar da população. Este fato impede a atuação coordenada das políticas públicas, ou seja, em transversalidade com as demais políticas (meio ambiente, economia, direitos humanos). O contexto pandêmico potencializou de forma negativa a descoordenação e contribuiu para o aumento de demandas judiciais e para um personalismo do chefe do Poder Executivo federal que dificulta o enfrentamento da crise sanitária.

Ressalta-se que o sentido de transversalidade de uma política pública em relação a grupos vulneráveis, que consiste no fornecimento pelo Estado de uma gestão pública adequada nos casos em que a organização clássica não consegue suprir as suas demandas, reside em compreender que os povos originários precisam receber um tratamento diferenciado pelo SUS.

O subsistema de saúde instituído pelo SUS, implementado pela Lei $n^{\circ}$ 9.836, de 1999, precisa ser aperfeiçoado. Isso significa levar em consideração todas as necessidades específicas dessas populações para que se possa formular uma abordagem diferenciada e global de acordo com o seu modelo cultural. O financiamento específico a esse grupo de vulneráveis será de responsabilidade da União, e o SUS servirá como suporte para compreender todos os níveis de atuação da saúde necessários para o atendimento integral dessas comunidades, sendo adaptado a esses locais.

Ao examinar a ADPF $\mathrm{n}^{\circ} 709$, o ministro Luís Roberto Barroso apresenta argumentos que descrevem a complexidade da crise sanitária. Primeiro, destaca a necessidade e a ausência de um diálogo intercultural, o qual permitiria que o governo federal, através de suas agências Funai e Sesai, ouvisse os povos indígenas sobre suas necessidades sanitárias e especificidades culturais. Segundo, compreende que para qualquer tomada de decisão que 
envolva os povos indígenas deve integrar a sua participação, especialmente de suas lideranças. Finalmente, ressalta que o Estado deve retirar imediatamente os invasores das terras indígenas, porque a presença deles estaria violando direitos constitucionais dos povos originários à terra, a sua cultura, a sua subsistência tradicional $\mathrm{e}$, ainda, os expondo desnecessariamente a ameaças de morte e de contágio por COVID-19.

\section{Constitucionalização simbólica}

$\mathrm{Na} A D I n^{\circ}$ 6.343, o STF responde ao enfrentamento da pandemia com mecanismos constitucionais de equilíbrio institucional e manutenção da harmonia e independência entre os poderes. Com a fiel observância à separação de poderes e ao federalismo, como cláusulas pétreas - limitadoras do exercício arbitrário do poder -, suspende parcialmente, sem redução de texto, o artigo art. $3^{\circ}, \mathrm{VI}$, b e $\S \S 6^{\circ}$ e $7^{\circ}$, II da Lei $n^{\circ} 13.979 / 2020$, para excluir Estados e Municípios da necessidade de autorização da União ou de obediência a determinação de órgãos federais para adoção de medidas de restrição à circulação de pessoas.

Na ADPF $n^{\circ} 709$, o STF responde com os princípios da prevenção e da precaução, ressaltando risco iminente de extermínio em massa dos povos indígenas em decorrência da pandemia por COVID-19. Recomenda o respeito à autodeterminação dos povos, no sentido de preservar sua identidade e suas próprias organizações, usos, costumes e tradições. Destaca o direito ao isolamento das comunidades e o dever do Estado em assegurá-lo. Assim, determina a criação de barreiras sanitárias que vedem a entrada e a saída de territórios de povos indígenas em isolamento e de contato recente. Determina, também, a criação de Sala de Situação, ressaltando que essa medida não significa interferência do Poder Judiciário sobre as políticas públicas, mas mera implementação judicial de norma federal, não observada pelo Poder Público federal. Por fim, o Tribunal enfatiza a norma supralegal que atribui a necessidade de participação dos povos indígenas no planejamento e na execução dos programas de saúde voltados às suas comunidades, que deixou de ser cumprida pelo Poder Público federal: a Convenção nº 169 Sobre povos indígenas e tribais, da Organização Internacional do Trabalho (OIT) (30). Dessa diretriz internacional, destaca o dever do Poder Público de assegurar os meios necessários para que as instituições responsáveis pela administração de programas no interesse de tais comunidades funcionem adequadamente.

\section{Conclusões}

A partir da decretação da pandemia da COVID-19, em 11 de março de 2020, pela Organização Mundial da Saúde, exigiu-se uma cooperação mundial e nacional de 
enfretamento à crise sanitária. Todavia, no contexto brasileiro, ao invés de tornar o país mais forte com uma governança pública qualificada, instalou-se no Poder Executivo federal um processo de alteração da lógica federativa, tanto que no início da constatação do vírus no país ignorou-se a capacidade destrutiva da doença, exemplificada em pronunciamento nacional, em 24 de março de 2021, que criticava o fechamento dos estabelecimentos e chamava a doença de gripezinha.

O confronto descoordenado entre as entidades federativas, representado pela ínfima competência na Administração Pública da crise sanitária e pela ausência de liderança governamental por parte do Poder Executivo federal, implicou no aumento de consequências danosas para com os direitos e garantias da população brasileira, influenciando, inclusive, nas estatísticas de óbitos e infectados, como apontado durante depoimentos na CPI da Pandemia. Dentre os fatores que permeiam os conflitos atuais da República Federativa brasileira, citam-se os duelos entre as entidades federativas e a União devido à centralização de poder. O delinear desses embates surge antes mesmo da declaração da pandemia de COVID-19, mas que com a ascensão do chefe do Poder Executivo, acabou por alterar a estabilidade institucional e acelerar o processo de crescimento das funções do Poder Executivo $(18,20)$.

O federalismo descoordenado caracteriza-se como um projeto autocrático do chefe do Poder Executivo, que reduz os espaços de diálogo, negociação e participação dos entes subnacionais. O exemplo emblemático está no julgado da $A D I n^{\circ} 6.386$, que como foi analisado, afirma que "nenhum ente federativo, nenhum Poder de Estado, nenhuma autoridade, tem o monopólio de combate à pandemia" (28)

Tal descoordenação não reconhece os direitos sociais de grupos vulneráveis, a exemplo dos povos originários, e é omisso em relação ao plano de enfrentamento da complexa realidade das aldeias indígenas, ou seja, um plano de enfrentamento que leve em conta as particularidades das diferentes etnias. Por conseguinte, não há políticas públicas de saúde sendo construídas no formato de planos estratégicos para atender as necessidades sanitárias dos povos originários.

Por fim, conclui-se que a crise sanitária, caracterizada pela descoordenação do federalismo em concentrar a organização das diretrizes de enfrentamento à pandemia (ADI $n^{\circ}$ 6.386) e pelas omissões em não atender as necessidades sanitárias dos povos originários (ADPF n 709), acentua-se com a constitucionalização simbólica dos julgados investigados, haja vista que, por mais que o sistema judicial responda à crise com mecanismos constitucionais que visem a manutenção da harmonia entre os poderes, há uma baixa concretização do direito à 
saúde de grupos vulneráveis, evidenciado na ausência de participação dos povos indígenas no planejamento e na execução das políticas públicas de saúde.

\section{Referências}

1. Center for Systems Science and Engineering (CSSE) at Johns Hopkins University (JHU). COVID-19 Dashboard. Disponível em: https://coronavirus.jhu.edu/map.html

2. Conselho Nacional de Secretários de Saúde (CONASS). Painel CONASS COVID-19. Disponível em: https://www.conass.org.br/painelconasscovid19/

3. Horton R. Offline: COVID-19 is not a pandemic. The Lancet. Set. 26, 2020; 396 (10255):874. Disponível em: https://doi.org/10.1016/S0140-6736(20)32000-6

4. Mendenhall E. The COVID-19 syndemic is not global: context matters. The Lancet. Nov. 28, 2020; 396(10264):1731. Disponível em: https://doi.org/10.1016/S0140-6736(20)322182

5. Rocha R, Atun R, Massuda A et al. Effect of socioeconomic inequalities and vulnerabilities on health-system preparedness and response to COVID-19 in Brazil: a comprehensive analysis. The Lancet Global Health. June 01, 2021; 9(6):e782-e792. Disponível em: https://doi.org/10.1016/S2214-109X(21)00081-4

6. Li Y, Campbell H, Kulkarni D et al. The temporal association of introducing and lifting non-pharmaceutical interventions with the time-varying reproduction number $(R)$ of SARSCoV-2: a modelling study across 131 countries. Lancet Infect Dis. 2021; 21:193-202. Disponível em: https://www.thelancet.com/journals/laninf/article/PIIS1473-3099(20)307854/fulltext

7. International Monetary Fund. Policy support and vaccines expected to lift activity. Jan. 2021. Disponível em: https://www.imf.org/en/Publications/WEO/lssues/2021/01/26/2021world-economic-outlook-update

8. Barberia LG, Gómez EJ. Political and institutional perils of Brazil's COVID-19 crisis. The Lancet. Ago. 08, 2020 [citado em 24 set.2021]; 396(10248):367-368. Disponível em: https://doi.org/10.1016/S0140-6736(20)31681-0

9. Hallal PC. SOS Brazil: science under attack. The Lancet. Jan. 30, 2021 [citado em 28 jul.2021]; 39(10272):373-374. Disponível em: https://doi.org/10.1016/S01406736(21)00141-0

10. The Lancet. COVID-19 in Brazil: "So what?". The Lancet. Mai. 09, 2020 [citado em 23 set.2021]; 395(10235):1461. Disponível em: https://doi.org/10.1016/S0140-6736(20)310953

11. Zimerman A, Lopes RD, D'ávila A, Rohde LE, Zimerman LI. COVID-19 in Brazil: the headlines should be about Science. The Lancet. dec. 05, 2020; 396(10265):1803.

Disponível em: https://doi.org/10.1016/S0140-6736(20)32375-8 
12. Centro de Estudos e Pesquisas de Direito Sanitário (Cepedisa). A linha do tempo da estratégia federal de disseminação da COVID-19. Relatório de pesquisa, 2021 [citado em 24 set. 2021]. Disponível em: https://cepedisa.org.br/wpcontent/uploads/2021/06/CEPEDISA-USP-Linha-do-Tempo-Maio-2021_v3.pdf

13. Ferrante L, Steinmetz WA, Almeida ACL et al. Brazil's policies condemn Amazonia to a second wave of COVID-19. Nat Med. 2020; 26:1315. Disponível em: https://doi.org/10.1038/s41591-020-1026-x

14. Taylor L. 'We are being ignored': Brazil's researchers blame anti-science government for devastating COVID surge. Nature. 27 April 2021. Disponível em:

https://www.nature.com/articles/d41586-021-01031-w

15. Matta GC, Rego S, Souto EP, Segata J (eds). Os impactos sociais da Covid-19 no Brasil: populações vulnerabilizadas e respostas à pandemia [online]. Rio de Janeiro: Observatório Covid 19, Editora Fiocruz; 2021. 221 p. ISBN: 978-65-5708-032-0.

16. Ribeiro MTA, Cabral CHPL. A dignidade humana frente às medidas sanitárias restritivas da OMS e dos estados em tempos de pandemia. Cadernos Eletrônicos Direito Internacional sem Fronteiras. Jan-Jun 2020 [citado em 10 julho de 2021]; 2(1):e:2. Disponível em: https://www.cadernoseletronicosdisf.com.br/cedisf/article/view/60

17. Silva R, Pasti D. Da "gripezinha" ao "e daí?": as falas de Bolsonaro em cada fase da pandemia. A Gazeta. 5 de maio de 2020. Disponível em:

https://www.agazeta.com.br/es/politica/da-gripezinha-ao-e-dai-as-falas-de-bolsonaro-emcada-fase-da-pandemia-0520

18. Abrucio FL et al. Combate à COVID-19 sob o Federalismo Bolsonarista: Um caso de descoordenação governamental. Revista de Administração Pública. Jul-Ago 2020 [citado em 12 de julho de 2021]; 54 (4). Disponível em:

https://www.scielo.br/j/rap/a/bpdbc9zSGCKZK55L3ChjVqJ/?lang=pt

19. Brasil. Constituição da República Federativa do Brasil. (1988). Disponível em: http://www.planalto.gov.br/ccivil_03/constituicao/constituicao.htm

20. Urbinati N. O que torna a representação democrática? Lua Nova, São Paulo, 67: 191228, 2006. Disponível em:

https://www.scielo.br/j/ln/a/4qsH3GhJPTTnmmMhJg8jkhB/?lang=pt\&format=pdf

21. Beraldo M. Governança Pública para garantir o financiamento dos direitos sociais em tempos de pandemia. Revista de Direito Administrativo e Gestão Pública. Jul/Dez. 2020 [citado em 25 de julho de 2021]; 6(2):82-99. Disponível em: https://www.indexlaw.org/index.php/rdagp/article/view/6988

22. Cortês SN, Araújo CS. In: Hirschi FPA (Org). As instituições estão funcionando? E daí? Reflexões sobre o Estado e as formas de governança na crise do covid-19. Covid-19 e o Direito na Bahia. Salvador: Editora Levando o Direito a sério, 2020. p. 175-189.

23. Neves M. Da Autopoiese à alopoiese do direito. Revista Brasileira de Filosofia. São Paulo: Instituto Brasileiro de Filosofia, 2011; XLII:117-141. 
24. Neves CE, Neves F. O que há de complexo num mundo complexo? Niklas Luhmann e a teoria dos sistemas sociais. Sociologias. jan./jun. 2006; 15:182-207.

25. Luhmann N. O direito na sociedade. São Paulo: M. Fontes; 2016.

26. Coacci T. A Pesquisa com Acórdãos nas Ciências Sociais: Algumas Reflexões Metodológicas. Mediações: Revista de Ciências Sociais. 2013; (18):2.

27. Ximenes JM. Levantamento dos dados na Pesquisa em Direito: a técnica da análise de conteúdo. Anais do XX Congresso Nacional do CONPEDI Tema:" A Ordem Jurídica Justa: um diálogo Euroamericano. 1ed. Florianópolis: Fundação Boiteux Volume 1 Páginas 76087622, 2011.

28. Brasil. Supremo Tribunal Federal (Tribunal Pleno). Acórdão. Referendo na Medida Cautelar na Ação Direta de Inconstitucionalidade $n^{\circ}$ 6.343/DF. Relator: Ministro Marco Aurélio. Redator do acórdão: Ministro Alexandre de Moraes. Julgamento: 6 de maio de 2020. Publicação: 17 nov. 2020. Disponível em:

http://portal.stf.jus.br/processos/detalhe.asp?incidente $=5881008$

29. Brasil. Supremo Tribunal Federal (Tribunal Pleno). Acórdão. Arguição de Descumprimento de Preceito Fundamental n 709/DF. Relator: Ministro Roberto Barroso. Julgamento: 21 jun. 2021. Publicação: 26 ago. 2021. Disponível em: http://portal.stf.jus.br/processos/detalhe.asp?incidente $=5952986$

30. Organização Internacional do Trabalho (OIT). Convenção n 169 - Sobre povos indígenas e tribais. Genebra, Suíça: OIT; 1989. Disponível em:

https://www.ilo.org/brasilia/convencoes/WCMS_236247/lang--pt/index.htm

\section{Colaboradores}

Ribeiro KD contribuiu com a concepção/desenho, redação do artigo, análise e interpretação dos dados, revisão crítica do conteúdo e aprovação da versão do artigo. Lima LC contribuiu com a análise e interpretação de dados, redação do artigo, revisão crítica do conteúdo e aprovação da versão final do artigo. Souza SMC e Pimentel KE contribuíram para a redação, revisão crítica do conteúdo e aprovação da versão final do artigo.

Ribeiro KD, Lima LC, Souza SMC, Pimentel KE. O caos sanitário da crise por COVID-19 no Brasil e o direito à saúde na jurisprudência da Corte. Cadernos Ibero-Americanos de Direito Sanitário. 2021 dez.;10 (Suplemento):116-133

https://doi.org/10.17566/ciads.v10iSuplemento.852 